Elina Magnan Barbosa ${ }^{1}$

\title{
RIGHT TO TRY? FOSFOETANOLAMINA, DI BELLA E STAMINA: UMA ANÁLISE ÍTALO-BRASILEIRA
}

Right to try? Phosphoethanolamine, di Bella and Stamina cases: an Italo-Brazilian analysis

${ }^{1}$ Universidade de Pisa. Pisa/Toscana, Itália.

Correspondência: Elina Magnan Barbosa. E-mail: elina_magnan@yahoo.com.br.

Recebido em: 24/05/2016. Revisado em: 06/07/2016. Aprovado em: 07/07/2016. 


\section{RESUMO}

Este trabalho possui como objetivo a análise do fornecimento judicial de medicamentos em fase de teste laboratorial, por meio de um estudo comparado dos casos italianos di Bella e Stamina e do caso brasileiro da fosfoetanolamina da Universidade de São Paulo. Para tanto, foram considerados os percursos judiciais dos três casos, as opiniões doutrinárias e repercussões médicas anunciadas pela mídia e pelos órgãos oficiais interessados. Como resultado, observou-se, no Brasil, uma tendência jurisprudencial que desponta, ainda que não confirmada, no sentido de que a realização do direito à saúde não pode prescindir da segurança médica, afastando-se, em princípio, a obrigação do Estado de fornecer tratamentos experimentais por meio de sua rede de saúde. Na Itália, por outro lado, após a experiência judicial e médica negativa decorrente de dois casos emblemáticos, a Corte Constitucional italiana (Corte Costituzionale) parece ter mudado de orientação, no sentido da não obrigação do fornecimento de tratamento experimental por parte do Servizio Sanitario Nazionale. No âmbito das ações com pretensão de curas compassivas, as normas técnicas, representadas pelas boas práticas clínicas, surgem como zíper de união entre o direito, a ciência e a ética.

\section{Palavras-Chave}

Boas Práticas Clínicas; Direito à Saúde; Tratamentos Experimentais.

\section{ABSTRACT}

This paper reports on an analysis of court orders that determine experimental therapies and provides a comparative study of the Italian Di Bella and Stamina cases and the Brazilian Phosphoethanolamine case. The judicial sentences on the three cases were considered, along with their medical outcome and media repercussion. As a result of the comparison, it was observed that the Brazilian Constitutional Court is tending towards the non-recognition of a "right to try", even though the Court's official opinion remains to be seen. In Italy, on the other hand, after the negative judicial and medical experience concerning two emblematic cases, the opinion of the Italian Constitutional Court seems to have changed, indicating that the State is no longer forced to provide experimental therapies through the public health system. In the scope of these judicial lawsuits that claim compassionate cures, the technical framework, represented by the good clinical practices guidelines, comes about as the "zipper" that binds together law, science and ethics.

\section{Keywords}

Experimental Treatments; Good Clinical Practices; Right to Health. 


\section{Introdução}

Vivemos, na atualidade, um momento de transição do direito, com o abandono de velhos paradigmas e o nascimento de novos direitos subjetivos. Surgem, assim, novas situações sociais que devem ser encobertas pelo direito e novos direitos fundamentais que criam cada vez mais obrigações para o Estado no que diz respeito a sua proteção e promoção.

No âmbito do direito, a saúde não caminha de forma diferente. Novas epidemias, curas novas para velhas doenças, liberdade de escolha terapêutica e o vagaroso, mas seguro caminho, que os tratamentos inovadores devem trilhar antes que possam ser reconhecidos e disponibilizados, somados à urgência da necessidade dos pacientes, tornam a realidade da concretização do direito à saúde ainda mais complexa. Sobretudo quando já se encontra solidificado seu caráter prestacional na maioria das constituições democráticas, impondo-se uma obrigação ao Estado de lhe dar vida e corpo, sem que se saiba jurídica e eticamente quais devam ser os seus limites.

Nesse contexto, diante da premente necessidade de se fazer valer o direito à saúde e perante o veloz desenvolvimento da ciência, surge, para o Estado e para os médicos, a necessidade de reconhecer um descompasso entre o curso normal de testes médicos experimentais e a urgência da espera individual por um tratamento. Aqui não pode ser encontrada resposta na medicina baseada em evidências, que sai de cena e dá lugar aos tratamentos experimentais, aos quakery products ${ }^{1}$ - enfim, a todo tipo de medicação não aprovada, cujas eficácia e segurança não são reconhecidas.

Desse modo, como tentativa de fazer valer o caráter prestacional e constitucional do direito à saúde, surge um "direito à esperança", como o apelidaram os tribunais italianos, ou, ainda, um right to try (direito de tentar) - como ficou conhecido o direito nos Estados Unidos, onde, em vários estados (Michigan, Missouri, Louisiana, Colorado e Arizona), foram promulgadas leis para facilitar o acesso de pacientes a tratamentos em fase de experimentação, sem incorrerem nos óbices da Food and Drug Administration (FDA, agência regulatória norte-americana para medicamentos e alimentação).

$\mathrm{O}$ "direito à esperança" ou às curas compassivas grava profundamente a Administração Pública, que se vê, de um lado, perante o dever de realizar um direito subjetivo sem limites e, de outro lado, perante a necessidade jurídica de atuar dentro dos contornos por ela mesma estabelecidos e sobre os quais se baseia a segurança jurídica num Estado de Direito. Nesse contexto, para o Estado, emerge como algo difícil, ou até mesmo impossível, o equilíbrio entre o dever de evitar uma

\footnotetext{
${ }^{1}$ Produtos pseudomédicos, promovidos de forma insistente e marqueteira.
} 
experimentação oculta, gravosa e ilusória, e a sensibilidade para com o desespero dos pacientes e familiares, que desejam tentar o possível e o impossível, ainda que, para tanto, mergulhem num túnel escuro de total desinformação científica.

Diante dessa conjuntura, resulta de suma importância a análise da experiência da Itália com o direito à esperança, a cure compassionevole - isto é, o percurso judicial italiano no campo do fornecimento obrigatório de tratamento experimental pelo Estado -, em confronto com a recente experiência do Brasil com a "pílula da USP".

Como ponto de partida, será exposto brevemente o caso da fosfoetanolamina. Em seguida, após breve menção do caso pioneiro Estados Unidos $\mathrm{x}$ Rutherford, serão apresentadas as respostas dadas pela Corte Constituzionale italianaitaliana a dois casos semelhantes ocorridos na Itália, ambos emblemáticos - o renomado caso di Bella e o recente caso Stamina, marcos da jurisprudência constitucional italiana referente ao direito à saúde. Finalmente, concluir-se-á com considerações a respeito do direito e da ciência médica.

\section{Caso da pílula do câncer}

A saga da judicialização da saúde no Brasil está atingindo um grau de complexidade e criatividade jamais contemplado. Ainda que o Supremo Tribunal Federal (STF) tenha vislumbrado problemas futuros, ao decidir na já datada Suspensão de Tutela Antecipada (STA) $175^{2}$ - e que o Conselho Nacional de Justiça (CNJ) tenha criado algumas orientações a serem seguidas nas ações de saúde e nos comitês nacionais para evitar a judicialização -, as demandas judiciais se multiplicam e assumem dimensões jamais imaginadas.

O caso mais recente, como a mídia nacional não para de relembrar a todo instante, é o da pílula do câncer: a fosfoetalonamina, substância produzida em laboratório do Instituto de Química da Universidade de São Paulo (USP), em São Carlos, e que vem sendo utilizada no tratamento da doença mesmo sem a devida aprovação da Agência Nacional de Vigilância Sanitária (Anvisa), em virtude de decisões judiciais que determinam seu fornecimento. Com a notícia de que a substância surtia efeitos positivos no tratamento do câncer, os pacientes não tardaram a recorrer ao Poder Judiciário para obrigar a universidade, que já havia suspendido seu fornecimento, a providenciar a distribuição da fosfoetanolamina.

O Tribunal de Justiça de São Paulo, diante das centenas de ações, acabou por suspender as liminares que determinavam o fornecimento da substância, obrigando os pacientes a recorrerem à Justiça Federal e à justiça de outros estados.

${ }^{2}$ SUPREMO TRIBUNAL FEDERAL. Suspensão de Tutela Antecipada (STA) 175. Disponível em: <http://www.stf. jus.br/arquivo/cms/noticianoticiastf/anexo/sta175.pdf>. Acesso em: 10 maio 2016. 
Esta decisão foi, contudo, igualmente suspendida pelo STF em voto do ministro Edson Fachin, que apontou em sua fundamentação que a ausência de registro junto à Anvisa não fere a ordem pública, ainda que seja assunto ainda pendente na Suprema Corte.

Em decisão do início do ano, entretanto, o Presidente do Tribunal, ministro Ricardo Lewandowski, determinou que a USP mantivesse o fornecimento da pílula do câncer somente até o fim do estoque. E entendeu que "atribuir a uma universidade pública a obrigação de fornecimento da substância a um número desconhecido de pessoas enfermas acaba por desviá-la das suas finalidades institucionais, nas quais, acredito, não consta a dispensação de medicamentos ou de substâncias para tratamento de saúde”3.

Para tentar resolver a questão do fornecimento da fosfoetanolamina sintética, o Congresso Nacional elaborou sucinta lei que entrou em vigor em abril de 2016, com o seguinte teor:

Art. $1^{\circ}$ Esta Lei autoriza o uso da substância fosfoetanolamina sintética por pacientes diagnosticados com neoplasia maligna.

Art. $2^{\circ}$ Poderão fazer uso da fosfoetanolamina sintética, por livre escolha, pacientes diagnosticados com neoplasia maligna, desde que observados os seguintes condicionantes:

I - laudo médico que comprove o diagnóstico;

II - assinatura de termo de consentimento e responsabilidade pelo paciente ou seu representante legal.

Parágrafo único. A opção pelo uso voluntário da fosfoetanolamina sintética não exclui o direito de acesso a outras modalidades terapêuticas.

Art. $3^{\circ}$ Fica definido como de relevância pública o uso da fosfoetanolamina sintética nos termos desta Lei.

Art. $4^{\circ}$ Ficam permitidos a produção, manufatura, importação, distribuição, prescrição, dispensação, posse ou uso da fosfoetanolamina sintética, direcionados aos usos de que trata esta Lei, independentemente de registro sanitário, em caráter excepcional, enquanto estiverem em curso estudos clínicos acerca dessa substância. Parágrafo único. A produção, manufatura, importação, distribuição, prescrição e dispensação da fosfoetanolamina sintética somente são permitidas para agentes regularmente autorizados e licenciados pela autoridade sanitária competente. Art. $5^{\circ}$ Esta Lei entra em vigor na data de sua publicação ${ }^{4}$.

${ }^{3}$ SUPREMO TRIBUNAL FEDERAL. Suspensão de Tutela Antecipada (STA) 828. Disponível em: <http://www. stf.jus.br/portal/processo/verProcessoAndamento.asp?numero $=828 \&$ classe $=S T A \&$ origem $=$ AP $\&$ recurso $=0$ \&tipoJulgamento=M>. Acesso em: 02 set. 2016.

${ }^{4}$ BRASIL. Lei $n$. 13.269, de 13 de abril de 2016. Autoriza o uso da fosfoetanolamina sintética por pacientes diagnosticados com neoplasia maligna. Disponível em: <http://www.planalto.gov.br/ccivil_03/_Ato20152018/2016/Lei/L13269.htm>. Acesso em: 23 maio 2016. 
Entretanto, em recentíssima decisão liminar, de maio de 2016, a pedido da Associação Médica do Brasil, no bojo da Ação Direta de Inconstitucionalidade (ADI) 5501 para declarar a inconstitucionalidade da referida lei, a Corte suspendeu a permissão para fornecimento da substância, seguindo voto de relatoria do Ministro Marco Aurélio Mello. Afirma o ministro:

A esperança depositada pela sociedade nos medicamentos, especialmente naqueles destinados ao tratamento de doenças como o câncer, não pode se distanciar da ciência. Foi-se o tempo da busca desenfreada pela cura sem o correspondente cuidado com a segurança e eficácia das substâncias. O direito à saúde não será plenamente concretizado sem que o Estado cumpra a obrigação de assegurar a qualidade das drogas distribuídas aos indivíduos mediante rigoroso crivo científico, apto a afastar desenganos, charlatanismos e efeitos prejudiciais ao ser humano ${ }^{5}$.

Ora, ainda que penda de julgamento definitivo, esta acertada decisão muda os contornos da jurisprudência do Supremo Tribunal Federal na matéria, aproximando-se da jurisprudência da Corte Constitucional italiana, do Corte Suprema norte-americana e da Corte de Estrasburgo, como será visto a seguir.

De todo modo, a partir da análise ainda que superficial das decisões judiciais sobre a pílula do câncer ao menos duas considerações são suscitadas: uma, de ordem jurídica e outra, de caráter médico. A primeira questão, com caráter jurídico e com eventual resposta mais direta dentro do ordenamento jurídico, refere-se à possibilidade de se obrigar o Estado a fornecer tratamento experimental gratuitamente à população. Aqui estão em jogo a garantia constitucional do direito à saúde e os limites da obrigação do Sistema Único de Saúde (SUS) e dos serviços sanitários nacionais para com seus pacientes.

A segunda questão que, de certa forma, apresenta-se como consequência lógica deste último raciocínio, levanta questionamentos de ordem médica, no sentido da possibilidade e da responsabilidade de um médico de prescrever um tratamento experimental a seu paciente, de um juiz de determiná-lo e do Estado de fornecê-lo, sem que exista protocolo a ser seguido, contraindicações a serem consideradas, dose a ser ministrada ou medicina baseada em evidências a servir como orientação geral.

De fato, não há dúvidas hoje de que toda a medicina contemporânea deve ser baseada em evidências, ou seja, uma Evidence Based Medicine ${ }^{6}$ que consubstancia o uso racional, explícito, judicioso e atualizado da melhor evidência científica, aplicada ao cuidado de pacientes individuais. No entanto, a medicina baseada em

${ }^{5}$ SUPREMO TRIBUNAL FEDERAL. Ação Direta de Inconstitucionalidade (ADI) 5501. Disponível em: <http://www. stf.jus.br/portal/processo/verProcessoAndamento.asp?incidente=4966501>. Acesso em: 23 maio 2016.

${ }^{6}$ Para mais detalhes, ver: EL DIB, Regina P. Como praticar a medicina baseada em evidências. J Vasc Bras, v. 6, n. 1, 2007. Disponível em: <http://www.scielo.br/pdf/jvb/v6n1/v6n1a01.pdf>. Acesso em: 23 maio 2016. 
evidências fica completamente relegada ao segundo plano quando entra em campo o afã desvairado dos pleitos judiciais para submissão a tratamentos experimentais, sobretudo no Brasil. As perguntas que devem ser feitas para orientar as reflexões, entretanto, são várias. Até que ponto se pode deixar ao juízo de um único médico, avalizado por um juiz, o recurso a terapias não permitidas? Qual a relação entre o direito à saúde e o direito à esperança? Qual a relação entre direito, ciência e ética?

Os casos italianos da multiterapia di Bella e da Stamina poderão servir de orientação e oferecer eventualmente alguma centelha de resposta pra esses questionamentos.

\section{Caso di Bella}

O primeiro caso italiano refere-se ao multitratamento antitumoral criado pelo professor Luigi di Bella, que causou grande comoção na Itália durante os anos de 1997 e 1998, atraindo atenção dos tribunais em diversas ações, dos operadores sanitários e da opinião pública. Dizia-se, à época, que di Bella teria descoberto uma cura para o câncer, válida e sem efeitos colaterais. O boato espalhou-se rapidamente nos idos de 1997 e logo os jornais e canais de televisão começaram a falar do novo método contra o câncer. A casa do professor foi tomada por doentes e suas famílias que desejavam experimentar o novo tratamento, que era realizado mediante uma contribuição livre por parte de cada paciente ${ }^{7}$.

Considerando os 250 mil casos diagnosticados de câncer na Itália, a sobrevida média de cinco anos após o diagnóstico e o percentual de cura de $30 \%$, não é difícil imaginar o efeito emocional que tal possibilidade de cura surtiu nos doentes e suas famílias ${ }^{8}$. No entanto, o custo dos fármacos que compunham o protocolo di Bella era altíssimo e proibitivo para a maioria das famílias?

Contagiado pelo afã emotivo das famílias e da mídia, o juiz Carlo Madaro, de Maglie, pequena cidade no Lecce, em decisão sem precedente de dezembro de 1997, impôs à Azienda Sanitaria Locale (ASL Lecce 2$)^{10}$ o fornecimento dos medicamentos previstos na cura di Bella a um menor, ainda que o tratamento não tivesse sido autorizado pelo ministério da saúde italiano. Tal sentença foi proferida ao acolher o recurso de um menino de dois anos com tumor cerebral para quem os ciclos tradicionais de quimioterapia não haviam surtido efeito e que desejava submeter-se ao tratamento com

\footnotetext{
${ }^{7}$ MEDBUNKER. Dossier di Bella. Disponível em: <http://medbunker.blogspot.it/p/dossier-di-bella.html>. Acesso em: 27 jun. 2016.

${ }^{8}$ AGENZIA ITALIANA DEL FARMACO. Multittrattamento di Bella: risultati della sperimentazione. Disponível em: <http://www.agenziafarmaco.gov.it/it/content/il-multitrattamento-di-bella-risultati-della-sperimentazione>. Acesso em: 03 mar. 2016.

${ }^{9}$ De acordo com as informações contidas no "Dossier di Bella", somente a somatostatina, em sua quantidade mensal, custaria à época aproximadamente 90 mil libras esterlinas. (MEDBUNKER. op. cit.).

${ }^{10}$ Órgão da rede pública italiana de saúde, equiparável a uma secretaria de saúde estadual.
} 
Etaxene, cujo princípio ativo é a somatostatina. Esta substância, essencial na terapia di Bella, tinha custo altíssimo e se encontrava disponível somente nos hospitais para o tratamento de algumas doenças específicas, como a pancreatite ${ }^{11}$.

A decisão do juiz de Maglie de conceder o Etaxene arrefeceu ainda mais os debates em torno da nova terapia e acabou por dar certa credibilidade, com contornos "oficiais", ao tratamento experimental. Assim, a partir dela, seguiram-se várias outras ações judiciais nas quais pacientes oncológicos solicitavam o custeio do tratamento com o protocolo di Bella. Somente o juiz Madaro julgou, nos meses sucessivos, mais 16 ações nesse mesmo sentido ${ }^{12}$.

Por outro lado, no início do ano de 1998, também como resultado da pressão midiática e das demandas judiciais, várias regiões da Itália começaram a fornecer gratuitamente o tratamento por meio de suas redes de saúde ${ }^{13}$. Dentre elas, podem ser citadas as regiões de Lecce, Puglia e Lombardia. Nessa mesma conjuntura, em decisão de 9 de fevereiro de 1998, o Tribunal Regional Administrativo (TAR) do Lazio estabeleceu que, também em sua rede de saúde, a substância deveria ser distribuída gratuitamente até o término da experimentação, em ambiente hospitalar, a doentes terminais ${ }^{14}$. O acórdão foi, todavia, impugnado pelo ministro da saúde, que submeteu a decisão ao Conselho de Estado italiano ${ }^{15}$.

Ao julgar o recurso do ministro, o Conselho de Estado italiano, $4^{\mathrm{a}}$ seção, entendeu que a decisão do Tribunal do Lazio merecia ser confirmada, mas que deveria ser analisada a questão da legitimidade constitucional do artigo $2^{\circ}$ do Decreto-Lei n. 23, que em tese a proibiria ${ }^{16}$. O artigo impugnado determinava que “em nenhum caso podem ser inseridos no elenco previsto pelo artigo $1^{\circ}$, parágrafo $4^{\circ}$, do Decreto-Lei n. 536, de 1996, medicamentos para os quais ainda não se encontrem disponíveis resultados de estudos clínicos de segunda fase"17,18. O mencionado elenco

${ }^{11}$ CASTELLANETA, Domenico. Pretore ordina la cura di Bella per un bimbo malato di tumore. La Repubblica, Itália, 17 dez. 1997. Disponível em: <http://ricerca.repubblica.it/repubblica/archivio/repubblica/1997/12/17/ pretore-ordina-la-cura-di-bella-per.html?refresh_ce>. Acesso em: 27 jun. 2016.

${ }^{12}$ DI BELLA. Cronistoria degli anni “caldi”. Dalle prime sperimentazioni alla "bocciatura” dell'Iss. Quotidiano Sanità, Itália, 27 fev. 2012. Disponível em: <http://www.quotidianosanita.it/cronache/articolo. php?approfondimento_id=1758>. Acesso em: 27 jun. 2016.

${ }^{13} \mathrm{O}$ Servizio Sanitario Nazionale italiano é composto por vários sistemas regionais que se reúnem juntamente com outros órgãos, sob a coordenação do Ministério da Saúde italiano.

${ }^{14}$ REPUBBLICA ITALIANA. Consiglio di Stato. Ordinanza 179/180. 24 fev. 1998. Disponível em: <http:// www.gazzettaufficiale.it/atto/corte_costituzionale/caricaArticolo?art.progressivo=0\&art.idArticolo=3\&art. versione=0\&art. codiceRedazionale=098C0244\&art. dataPubblicazioneGazzetta=1998-03-11\&art. idSottoArticolo=0>. Acesso em: 5 mar. 2016.

${ }^{15} \mathrm{O}$ Conselho de Estado (Consiglio di Stato) é órgão de segundo grau da justiça administrativa italiana e funciona como tribunal de apelação para as decisões dos TARs.

${ }^{16}$ REPUBBLICA ITALIANA. Consiglio di Stato. Ordinanza 179/180. 24 fev. 1998, cit.

${ }^{17}$ Os estudos ditos de "segunda fase" são aqueles realizados em seres humanos. (Tradução livre).

${ }^{18}$ REPUBBLICA ITALIANA. Decreto-Lei n. 23, de 17 de fevereiro de 1998. Disposições urgentes em matéria de experimentação científica clínica no campo oncológico e outras medidas sanitárias. Disponível em: <http://www.camera.it/parlam/leggi/98094l.htm>. Acesso em: 18 maio 2015. (Tradução livre). 
referia-se aos fármacos inovadores cujo comércio é autorizado em outros países, mas não no território italiano, e aqueles submetidos à experimentação clínica (ou off label) que devem ser fornecidos gratuitamente pelo Servizio Sanitario Nazionale quando não existir alternativa terapêutica válida.

Segundo o Conselho, a mencionada disposição violaria o artigo $3^{\circ}$ da Constituição italiana, por discriminação do tratamento di Bella, ao se exigir a conclusão de estudos de segunda fase e ao determinar seu fornecimento gratuito somente a pacientes hospitalizados e selecionados para a experimentação. Outro parâmetro invocado por ele foi o artigo 32 da Constituição Italiana, que se refere ao direito à saúde, em virtude do qual não seria possível, diante de sua fundamentalidade, negar a subministração de fármaco com alguma eficácia a doentes terminais. Ademais, o dispositivo normativo do decreto-lei acima indicado estaria igualmente em desacordo com os artigos 70 e 77 da Carta Italiana, pois teria vindo ao ordenamento jurídico por meio de decreto autônomo ${ }^{19}$. Com essas alegações, o Conselho de Estado italiano suscitou questão de constitucionalidade à Corte Constitucional Italiana.

A Corte Constitucional, a seu turno, diante dos argumentos do Conselho de Estado acima descritos, entendeu que não haveria ofensa constitucional quanto à exigência de cumprimento da "fase experimental II" para o fornecimento gratuito de fármacos alternativos, além de não se tratar na espécie de decreto autônomo. Tampouco, segundo seu entendimento, teria ocorrido discriminação do tratamento di Bella, pois a exigência legal de realização da fase experimental em seres humanos refere-se a todos os tratamentos inovadores, e não somente ao multitratamento di Bella ${ }^{20}$.

Por outro lado, entretanto, a Corte italiana reconheceu ofensa aos artigos $3^{\circ}$ (princípio da igualdade) e 32 (direito à saúde) da Constituição Italiana, na medida em que o legislador infraconstitucional teria feito a previsão de fornecimento gratuito do multitratamento somente aos sujeitos anteriores da experimentação, excluindo outros eventuais pacientes terminais que teriam de custeá-lo com meios próprios ${ }^{21}$. Explicou a Corte:

Ora, nos casos de exigências terapêuticas extremas, urgentes e sem resposta alternativa, como aquelas que se verificam em algumas patologias tumorais, deve ser considerado que da disciplina da experimentação, assim prevista, decorram indubitavelmente expectativas incluídas no conteúdo mínimo do direito à saúde. Não se pode admitir, entretanto, por força do princípio da igualdade, que o concreto gozo de tal direito fundamental dependa,

${ }^{19}$ REPUBBLICA ITALIANA. Consiglio di Stato. Ordinanza 179/180. 24 fev. 1998, cit.

${ }^{20}$ REPUBBLICA ITALIANA. Corte Costituzionale. Sentenza n. 185 del 1998. Redattore Guizzi. 20 maio 1998. Disponível em: <http://www.diritto.it/varie/dibella/sentenza_185_98.html>. Acesso em: 15 maio 2015.

${ }^{21}$ REPUBBLICA ITALIANA. Costituzione della Repubblica Italiana. Disponível em <http://www.quirinale.it/ qrnw/statico/costituzione/pdf/Costituzione.pdf>. Acesso em: 03 fev. 2015. 
para os sujeitos interessados, das diversas condições econômicas. Sob o perfil da garantia constitucional da saúde como direito, em relação ao campo oncológico, nem o parágrafo $3^{\circ}$ do artigo $3^{\circ}$ do decreto-lei e a previsão do art. 4 , voltada à determinação de um preço reduzido de venda dos medicamentos que fazem parte do multitratamento Di Bella, acordado entre o Ministro da Saúde e as empresas farmacêuticas, nem o valor destinado às prefeituras para financiar as despesas sanitárias dos indigentes, parecem suficientes ${ }^{22}$. (Tradução livre)

Com essa decisão, materializada no acórdão 185 de 1998, a Corte Constitucional entendeu que o tratamento di Bella, por força do princípio da isonomia e do direito à saúde, deveria ser estendido a todos que dele necessitassem, obrigando assim o Estado a prestá-lo gratuitamente a todos pacientes terminais ou sem alternativa terapêutica.

O fenômeno di Bella, todavia, diferentemente do que se possa imaginar à primeira vista, não foi exclusivamente italiano. De fato, já havia acontecido anteriormente nos Estados Unidos nos anos 1970, com o caso Laetrile ${ }^{23}$, referente ao extrato do caroço de abricó - que, pela repercussão que teve, pode ser considerado idêntico ao caso italiano estudado.

No caso ocorrido nos Estados Unidos, entretanto, a Suprema Corte norte-americana decidiu de forma diametralmente oposta à Corte italiana. Isto é, longe de reconhecer a obrigação estatal de fornecer a todos o tratamento experimental, a Corte americana decidiu que a comercialização e venda de drogas e tratamentos novos, ainda que para pacientes terminais, deveriam seguir determinados requisitos científicos e serem aprovados pela FDA antes que pudessem ser disponibilizados. Com tal orientação, excluiu como consequência a obrigação do Estado relativa ao fornecimento de terapia experimental, ou seja, de terapias cujas fases de teste ainda não tenham sido completamente concluídas e daquelas não aprovadas pela FDA. $\mathrm{O}$ voto do juiz Marshall é de grande interesse e entendeu que não se poderiam excluir as normas da FDA para drogas novas, ainda que para pacientes oncológicos desenganados e terminais ${ }^{24}$.

\footnotetext{
${ }^{22}$ REPUBBLICA ITALIANA. CORTE COSTITUZIONALE. Sentenza n. 185 del 1998, cit.

${ }^{23}$ UNITED STATES. SUPREME COURT. United States v. Rutherford (1979) No. 78-605. Argued: April 25, 1979. Decisão: Junho 18, 1979. Disponível em: <http://caselaw.findlaw.com/us-supremecourt/442/544.html>. Acesso em: 15 fev. 2016. Para aprofundamento na matéria, v.: ETERSEN, James C.; MARKLE, Gerald E. Politics and science in the Laetrile Controversy. Social Studies of Science, n. 9, p. 139-166, May, 1979. Disponível em: <http://sss.sagepub.com/>. Acesso em: 29 fev. 2016. RELMAN, A. Closing the books on Laetrile. New England Journal of Medicine, n. 306, p. 236, 1982. 10.1056/NEJM198201283060410.

${ }^{24}$ Id. Ibid.
} 


\section{Confira-se parte do voto de Marshall:}

Uma droga é eficaz dentro do significado de 201 (p) (1) se existe um reconhecimento geral dentre os especialistas, fundado em evidência substancial, que a droga de fato produz os resultados alegados em certas condições especificadas. Veja Weinberger $v$. Hynson, Westcott e Dunning, inc, 412 U.S., at 629; n. 7, supra. Contrariamente ao que assume a Corte de Apelação, v. 582 F.2d, em 1236, eficácia não implica necessariamente capacidade de cura. No tratamento de qualquer doença, terminal ou não, uma droga é eficaz quando preenche, por critérios objetivos, a alegação de vida prolongada de seu patrocinador, melhoria da condição física ou redução da dor.

[...] Do mesmo modo, o conceito de segurança sob o 201 (p) (1) também possui significado para pacientes terminais. Poucas drogas, se é que existe alguma, são completamente seguras no sentido de poder ser usadas por todas as pessoas em todas as circunstâncias sem riscos. Assim, o Comissário (da FDA) geralmente considera uma droga segura quando o ganho terapêutico justifica os riscos compreendidos na sua utilização. Para (442 U.S. 544,556) os doentes terminais, assim como para todos os demais, uma droga é insegura se seu potencial para causar morte ou dano físico não for contrabalançado pela possibilidade de benefício terapêutico.

[...] Aceitar o argumento de que os parâmetros de segurança e eficácia do Ato (da FDA) não têm relevância para pacientes terminais é negar a autoridade do Comissário sobre todas as drogas, ainda que tóxicas e sem efeito (442 U.S. 544, 558), para tais indivíduos. Se a História puder ensinar alguma coisa, esse novo mercado não ficará desatendido. Desde a virada do século, engenhosos empreendedores têm feito propaganda de uma variada gama de curas simples e indolores para o câncer; amônia; musgo de turfa; lâmpadas coloridas; pastas feitas com glicerina e queijo limburger; comprimidos minerais; e misturas de especiarias, óleo e sebo, do tipo "Fonte da Juventude". Citando esses exemplos, não temos a intenção, é claro, de depreciar a sinceridade daqueles que propõem o tratamento com o Laetrile ou fazer implicação de que essa droga possa por fim provar-se segura e eficaz para o tratamento do câncer. Mas a experiência histórica sugere realmente que o Congresso (legislador) poderia ter razoavelmente decidido proteger os doentes terminais de uma vasta gama de panaceias que mentes férteis podem inventar ${ }^{25}$. (Tradução livre)

${ }^{25}$ UNITED STATES. SUPREME COURT. United States v. Rutherford (1979) No. 78-605. Argued: April 25, 1979, cit. 
Assim como no caso americano - em que, pouco tempo depois, estudos científicos ${ }^{26}$ demonstraram a total ineficácia do tratamento com o Laetrile, ou vitamina B17 -, também no caso do multitratamento di Bella os experimentos levados a cabo em nível nacional pelo Istituto Superiore di Sanità demonstraram seu total descabimento.

No caso italiano, foram testados 395 pacientes, de março a julho de 1998, dos quais somente três apresentaram uma resposta parcial ao tratamento, o equivalente a $0,8 \%$. Além disso, o tratamento foi suspenso após poucos meses em $85 \%$ dos pacientes por intoxicação ou morte. Alguns pacientes terminais foram posteriormente incluídos nos testes, por decisões judiciais, mas não houve qualquer benefício ou diminuição da atividade tumoral decorrente do tratamento ${ }^{27}$.

Os resultados experimentais dessas pesquisas foram divulgados em julho e novembro de 1998 e foram publicados no British Medical Journal. O veredicto foi claro: a terapia di Bella não só resultou inócua, como, também, antecipou a morte dos doentes que foram submetidos a esse tratamento em comparação com os submetidos à terapia tradicional ${ }^{28}$.

No mesmo ano, como decorrência desses resultados negativos, o médico di Bella concordou em abrir os arquivos com os registros médicos de pacientes tratados por ele desde o início da década de 1970 até 1997. Foram encontradas 3.076 pastas (e não 20 mil, como ele afirmava em talk shows), das quais somente 248 eram analisáveis. Isso porque muitas delas não continham diagnóstico, constatavam a presença de doenças não cancerosas ou, ainda, não relatavam quaisquer detalhes sobre o uso do tratamento. Desses 248 casos analisados, somente um indivíduo se encontrava vivo dois anos após o início da terapia, ratificando, assim, os resultados obtidos nos testes oficiais: o multitratamento di Bella não trazia benefício para os pacientes e, ainda, causava efeitos colaterais ${ }^{29}$.

Apesar disso, mesmo após os resultados negativos do experimento oficial com o multitratamento di Bella, alguns pacientes ainda hoje continuam a pedir judicialmente o tratamento e a encontrar sucesso em seu pleito ${ }^{30}$.

\footnotetext{
${ }^{26}$ Para mais detalhes, ver: MOERTEL, C. et al. A clinical trial of amygdalin (Laetrile) in the treatment of human cancer. New England Journal of Medicine, v. 306, n. 4, p. 201-206, Jan. 1982. 10.1056/ NEJM198201283060403.

${ }^{27}$ REPUBBLICA ITALIANA. Ministero della Sanità. Bollettino d'informazione sui farmaci. II Multitrattamento Di Bella - risultati della sperimentazione. Disponivel em <http://www.salute.gov.it/imgs/C_17_pubblicazioni_251_ allegato.pdf>. Acesso em: 10 ago. 2015.

${ }^{28}$ Id. Ibid.

${ }^{29}$ Id. Ibid.

${ }^{30}$ Dentre aquelas mais recentes, podemos citar as decisões do Tribunal de Brindisi de outubro e de julho de 2015 e aquelas dos tribunais de Foggia e de Lecce, respectivamente, de dezembro e janeiro de 2014. Para outras ações cominatórias referentes ao método di Bella, ver: PORTALE Médico Scientifico della Associazione "Giuseppe di Bella". Sentenze giudiziarie a favore di pazienti in cura. Disponível em: <http:// http://www.metododibella.org/it/SENTENZE-GIUDIZIARIE-a-favore-di-pazienti-in-cura.html>. Acesso em: 14 jan. 2016.
} 


\section{Caso Stamina (2015)}

O caso Stamina - que, de certo modo, é uma herança jurídica do caso precedente - teve início em setembro de 2011, após um acordo de colaboração entre a Azienda Ospedaliera Spedali Civili di Brescia e a Stamina Foundation Onlus, fundação atuante na pesquisa de terapias complexas e que trabalhava com terapias inovadoras baseadas em células-tronco mesenquimais preparadas num laboratório do hospital de Brescia, segundo um método novo elaborado pela própria entidade ${ }^{31}$. Esse convênio era decorrência do Decreto Ministerial de 5 de dezembro de 2006, que disciplinou o uso de medicamentos para terapias com genes e terapias celulares somáticas ainda não autorizadas para o comércio ${ }^{32}$. Como sujeitos possíveis para a experimentação, o artigo $1^{\circ}$ do decreto estabeleceu os pacientes sem alternativa válida de terapia, nos casos de urgência e de emergência que os colocassem em perigo de vida ou de grave dano à saúde, e nos casos de patologias graves e progressivas ${ }^{33}$.

Esses testes, que foram realizados com 12 pacientes (dentre eles quatro pediátricos), foram autorizados pela Agenzia Italiana del Farmaco (AIFA) ${ }^{34} \mathrm{e} \mathrm{conti-}$ nuaram até o ano de 2012. Em maio do mesmo ano, foi realizada inspeção local pela Procuradoria de Turim, na qual foram descobertas inúmeras violações - dentre elas, a ausência de comprovação da inexistência de terapia alternativa para os pacientes escolhidos, inexistência de declaração do médico prescritor e insubsistência dos dados científicos publicados em revistas internacionalmente acreditadas e que justificassem o recurso ao protocolo Stamina. Como consequência, a AIFA proferiu

\footnotetext{
${ }^{31}$ GIUPPONI, Lisa. Stamina, storia di una vicenda italiana: terapie staminali e diritto alla salute. Disponível em: <http://www.macsis.unimib.it/wp-content/uploads/2014/01/Revisione-1-Lisa- Giupponi-StaminaStoria-di-una-vicenda-italiana-.pdf>. Acesso em: 17 mar. 2016; CAPOCCI, M; CORBELLINI, G. Le cellule della speranza: il caso Stamina tra inganno e scienza. Torino: Codice Edizioni, 2014. 192p. D'AMICO, G. Caso Stamina: la lotta per la salute. Disponível em: <http://www.forumcostituzionale.it/>. Acesso em: 01 fev. 2016. D'AMICO, G. II voto compassionevole del diritto e la dura scientia: a proposito del metodo Stamina. Quad. Cost, n. 2, p. 420-424, 2013. FALLETTI, Elena. Riflessioni sulle possibili cause del cortocircuito giuridico-istituzionale provocato dalla vicenda Stamina. Questione di Giustizia. Magistratura Democratica. Disponível em: <http://www.questionedigiustizia.it/>. Acesso em: 15 fev. 2016. PACE, T. Diritto alla salute o alla speranza? L'accesso al metodo Stamina per i pazienti affetti da patologie incurabili. Nuova Giur. Civ, n. 2, p. 133-138, Feb. 2014. TOMASI, M. II diritto alla salute fra comprensione del bisogno e ragioni della scienza: note a margine della vicenda Stamina. Rassegna di diritto pubblico europeo, anno 12, n. 1, p. 63-85, genn./giug. 2013. VARONESI, Paolo. Al crocevia del caso Stamina e dei suoi problemi costituzionali. Disponível em: <http://www.forumcostituzionale.it/wordpress/wp-content/ uploads/2015/01/veronesi.pdf>.

${ }^{32}$ REPUBBLICA ITALIANA. PARLAMENTO. Decreto 5 dicembre 2006. Utilizzazione di medicinali per terapia genica e per terapia cellulare somatica al di fuori di sperimentazioni cliniche e norme transitorie per la produzione di detti medicinali. Disponível em <http://www.gazzettaufficiale.it/eli/ id/2007/03/09/07A02073/sg>. Acesso em: 12 jan. 2016.

${ }^{33}$ Id. Ibid.

${ }^{34} \mathrm{~A}$ Agenzia Italiana del Farmaco (AIFA) é a autoridade sanitária com competência para realizar a atividade regulatória de fármacos na Itália. (REPUBBLICA ITALIANA. MINISTERO DELLA SALUTE. Agenzia Italiana del Faraco. Disponível em: <http://www.agenziafarmaco.gov.it/it/content/lagenzia-italiana-del-farmaco>. Acesso em: 28 jun. 2016.
} 
a decisão n. 1, de 15 de maio de $2012^{35}$, na qual decidiu interromper o tratamento com o protocolo Stamina.

Com a proibição de continuidade de sua cura, os pais dos menores que estavam sendo tratados com as células-tronco, assim como alguns adultos, ajuizaram ações judiciais com o intuito de poderem prosseguir com a terapia. Em alguns casos, obtiveram resposta positiva da parte dos tribunais, que declararam a supremacia do direito à saúde dos pacientes em relação ao interesse público tutelado pelo órgão administrativo ${ }^{36}$.

Em outros casos, entretanto, os pleitos de submissão ou continuação do tratamento Stamina foram rechaçados pelos tribunais. O Tribunal Regional Administrativo de Brescia, por exemplo, dando prevalência ao princípio da cautela, indeferiu o pedido de três menores de suspender a decisão da AIFA que impedia a continuação do tratamento. Na sua motivação, explicou que a suspensão imposta pela Agência baseou-se no fato de que o método e utilização das células-tronco usadas na terapia Stamina não dispunham de reconhecimento da comunidade científica internacional e não haviam superado certas fases de experimentação ${ }^{37}$. Do mesmo modo entenderam os tribunais de Trento ${ }^{38}$, Bolonha ${ }^{39}$, Pavia $^{40}$, Nuorso $^{41}$ e Turim $^{42}$.

Para solucionar o problema dessas decisões judiciais díspares, o Governo interveio com o Decreto-Lei n. 24, de março de $2013^{43}$, convertido com modificações na Lei n. 57, de 23 de maio de 2103, que criou uma dupla via de acesso ao método Stamina. Na verdade, a lei permitiu a continuação da terapia para os pacientes já a ela submetidos, e determinou a realização de uma experimentação clínica oficial com o mesmo método, que deveria iniciar-se em julho de 2013 e prosseguir por 18 meses $^{44}$.

\footnotetext{
${ }^{35}$ REPUBBLICA ITALIANA. AGENZIA ITALIANA DEL FARMACO. Ordinanza 01/2012. Disponível em: <http:// www.agenziafarmaco.gov.it/sites/default/files/ordinanza_1-2012.pdf>. Acesso em 23 maio de 2016.

${ }^{36}$ Tribunal de Venezia, Sez. Lav., 30 agosto 2012, Tribunal de Matera, sez. lav., 8 outubro 2012, Tribunal de Roma, Sez. Lav., ord. 16 novembro 2012, Tribunal de Trento, 20 novembro 2012. Disponíveis em: <http:// www.biodiritto.org.>. Acesso em: 12 out. 2015.

${ }^{37}$ REPUBBLICA ITALIANA. TAR BRESCIA. Ordinanza n. 414, 5 settembre 2012. Disponível em: <http://www. biodiritto.org>. Acesso em: 27 jun. 2016.

${ }^{38}$ REPUBBLICA ITALIANA. TRIBUNALE DI TRENTO. Ordinanza 11 febbraio 2013. Disponível em: <http://www. biodiritto.org>. Acesso em: 27 jun. 2016.

${ }^{39}$ REPUBBLICA ITALIANA. TRIBUNALE DI BOLOGNA. Sez. lavoro. Sent., 10-07-2013.Disponível em: <http:// www.biodiritto.org>. Acesso em: 27 jun. 2016.

${ }^{40}$ REPUBBLICA ITALIANA. TRIBUNALE DI PAVIA. Ordinanza del 17 settembre 2013.Disponível em: <http:// www.biodiritto.org>. Acesso em: 27 jun. 2016.

${ }^{41}$ REPUBBLICA ITALIANA. TRIBUNALE DI NUORO. Ordinanza 07 ottobre 2013. Disponível em: <http://www. biodiritto.org>. Acesso em: 27 jun. 2016.

${ }^{42}$ REPUBBLICA ITALIANA. TRIBUNALE DI TORINO. Sez. lavoro. 10 marzo 2014. Disponível em: <http://www. biodiritto.org>. Acesso em: 30 jun. 2016.

${ }^{43}$ REPUBBLICA ITALIANA. PARLAMENTO. decreto-Legge 25 marzo 2013, n. 24. Disposizioni in materia sanitaria. Disponível em: <http://www.gazzettaufficiale.it/eli/id/2013/03/26/13G00064/sg>. Acesso em: 20 maio 2016.

${ }^{44}$ Para aprofundamento na cronologia das normas e decisões judiciais relativas ao caso Stamina, ver: DOSSIER Stamina. Disponível em: <http://www.biodiritto.org/novita/news/item/330-dossier-staminali>. Acesso em: 28 jun. 2016.
} 
Apesar da regulamentação superveniente, de acordo com algumas decisões de primeiro grau, restou ainda, aos pacientes, a janela da relação entre a nova lei e o anterior decreto de 5 de dezembro de 2006, nos termos do seu artigo $1^{\circ}$, parágrafo $4^{\mathrm{o} 45}$, que possibilitava o início de novos tratamentos em casos de urgência e ausência de tratamento alternativo.

Em apertada síntese, as decisões referentes ao caso podem ser agrupadas em cinco tipos ${ }^{46}$ :

(a) Decisão que acolheu e estendeu o tratamento também a quem não tinha direito, e o fez após a intervenção legislativa.

(b) Decisão que acolheu e propôs a questão de legitimidade constitucional por violação do artigo $3^{\circ}$ da Constituição italiana, por disparidade de tratamento entre possíveis pacientes da terapia.

(c) Decisão que rejeitou o tratamento pleiteado porque a lei em vigor autoriza a continuação somente dos tratamentos em curso.

(d) Decisão que rejeitou o tratamento por ausência dos requisitos científicos requeridos pela legislação.

(e) Decisão que acolheu e determinou a subministração da terapia Stamina, mas perante cell factories autorizadas.

Para impactar em definitivo esse cenário judicial, em seguida à edição do decreto, o Tribunal de Tarento concedeu liminar em pleito cujo pedido principal referia-se à submissão à terapia Stamina por parte de pessoa que sofria de esclerose lateral amiotrófica (ELA), doença para a qual a medicina tradicional não oferecia tratamento. Ao concedê-la, a mencionada Corte entendeu que o ato normativo havia tido a intenção de regular completamente a matéria e que teria, portanto, revogado a normativa anterior. Suscitou, ademais, questão de constitucionalidade à Corte Constitucional italiana, por suposta ofensa ao princípio da igualdade e ao direito à saúde $^{47}$. Tal entendimento encontrou respaldo na doutrina e nos trabalhos preparatórios para a conversão do referido decreto em lei. Tribunais de outras regiões, contudo, resolveram a questão com uma interpretação conforme, estendendo os

\footnotetext{
${ }^{45}$ REPUBBLICAITALIANA. PARLAMENTO. Decreto 5 dicembre 2006. Utilizzazione dimedicinaliperterapia genica e per terapia cellulare somatica al di fuori di sperimentazioni cliniche e norme transitorie per la produzione di detti medicinali. Disponível em: <http://www.gazzettaufficiale.it/eli/id/2007/03/09/07A02073/sg>. Acesso em: 12 jan. 2016.

${ }^{46}$ DEMURO, G. La ricerca scientifica e il diritto alla salute. Rivista Telematica Giuridica dell' Associazione Italiana dei Costituzionalisti, n. 4, p. 6, 06/12/2013. Disponivel em: <http://www.associazionelucacoscioni. it/sites/default/files/documenti/4_2013_DeMuro.pdf>.

${ }^{47}$ REPUBBLICA ITALIANA. TRIBUNALE DI TARANTO. Sez. lavoro. Ordinanza del 24 settembre 2013. Disponível em: <https://www.personaedanno.it/attachments/article/43617/stamina_700.PDF>. Acesso em: 01 jul. 2016.
} 
efeitos do novo decreto convertido a pacientes ainda não submetidos ao tratamento, embora houvesse em seu texto uma disposição literal contrária ${ }^{48}$.

A Corte Constitucional, por sua vez, acolheu a relevância da questão de constitucionalidade levantada pelo Tribunal de Tarento, no sentido de que era necessário definir se os critérios, definidos pelo legislador para determinar o prosseguimento do tratamento Stamina para os pacientes antigos, causariam desarrazoada lesão ao direito à saúde dos pacientes não incluídos na previsão normativa, ofendendo, assim, os artigos $3^{\circ}$ e 32 da Constituição Italiana (isonomia e direito à saúde) ${ }^{49}$.

Ao julgar a questão de constitucionalidade, a Corte Suprema reiterou por sua vez o entendimento por ela esposado na sentença n. 282 de $2002^{50}$, na qual estabeleceu que, ao legislador, não fica preclusa a possibilidade de ditar regras sobre a adequação das escolhas terapêuticas, mas que deve fazê-lo após prévia verificação do conhecimento científico em questão, das evidências acolhidas nos experimentos, por meio dos órgãos científicos nacionais e internacionais. Dessa maneira, o dado científico constituiria um limite à discricionariedade política do legislador e sua ausência poderia invalidar uma lei. Acrescentou que a subministração de novos medicamentos deve seguir critérios rigorosos de cautela:

\footnotetext{
${ }^{48}$ V. Tribunal de Chiavari, 10 junho 2013: "tale intervento normativo non pare aver tenuto conto del valore direttamente precettivo e fondamentale dei valori costituzionali che la materia deve necessariamente affrontare affidando il riconoscimento di un diritto al trattamento di per sé validato, sostanzialmente a criteri influenzati da fattori cronologici (come l'aver già iniziato il trattamento, l'aver ottenuto un provvedimento giudiziario, l'essere inseriti in una futura sperimentazione...) che appaiono peraltro slegati da valutazioni strettamente collegate alla patologia e alla sua evoluzione nel tempo (chi ha già avuto accesso al trattamento potrebbe esser persona meno grave o malata da meno tempo di chi chiede ora l'accesso o aver ottenuto un provvedimento giudiziario favorevole in tempo anteriore per variabili anche indipendenti dallo stato di salute)". "Ciò premesso i valori fondamentali e costituzionalmente garantiti, in particolare, di cui agli art. 2, 3, 32 della Costituzione [...] devono essere [...] ritenuti del tutto prevalenti, nel riconoscere anche ai malati la cui situazione non è immediatamente riconducibile a quelle riportate dalla nuova normativa vigente, il diritto ad ottenere quanto richiesto". (VETTORI, Nicoletta. Sistema normativo aperto, rigore del metodo scientifico e diritto alla salute: il difficile ruolo di mediazione delle istituzioni pubbliche (a proposito del caso Stamina). Biolaw journal, Rivista di Biodiritto, n. 1 2015. Disponível em: <http://www.biodiritto. org/ojs/index. php?journal=biolaw\&page=article\&op=view\&path $\% 5 B \% 5 D=51 \&$ path $\% 5 B \% 5 D=44)$. (Tradução da autora: "esta intervenção normativa parece não ter levado em conta o valor diretamente prescritivo e fundamental dos valores constitucionais, que a matéria deve necessariamente afrontar com o reconhecimento de um direito ao tratamento válido por si mesmo, ao correlacioná-lo substancialmente a critérios influenciados por fatores cronológicos (como já ter iniciado o tratamento, ter obtido uma decisão judicial favorável, estar inserido em um futuro experimento etc.) que aparecem, ademais, desligados de avaliações estritamente relativas à patologia e a sua evolução no tempo (quem já obteve acesso ao tratamento pode ser pessoa menos doente ou doente há menos tempo do que a pessoa que pede acesso agora, ou haver obtido uma decisão judicial favorável com fundamentação baseada em aspectos não relacionados ao seu estado de saúde). Assim, os valores fundamentais e constitucionalmente garantidos, em particular aqueles referentes aos artigos 2o, 30 e 32 da Constituição [...] devem [...] prevalecer de tal modo a se reconhecer também aos doentes cuja situação não se enquadra imediatamente na previsão da norma vigente, o direito de obter o tratamento solicitado".)

${ }^{49}$ REPUBBLICA ITALIANA. CORTE COSTITUZIONALE. Sentenza n. 274 del 2014. Disponível em: <http://www. cortecostituzionale.it/actionSchedaPronuncia.do?anno=2014\&numero=274>. Acesso em: 20 jan. 2016.

${ }^{50}$ REPUBBLICA ITALIANA. CORTE COSTITUZIONALE. Sentenza n. 282 del 2012. Disponível em: <http://www. cortecostituzionale.it/actionSchedaPronuncia.do?anno=2002\&numero=282>. Acesso em 4 jan. 2016.
} 
a promoção de experimentação clínica para testar a eficácia e excluir efeitos colaterais nocivos de um fármaco não consente, em regra, a colocação antecipada de tratamento com ele a cargo de estruturas públicas: isso, por evidentes motivos de tutela da saúde, somado a exigências de correta utilização e destinação dos fundos e dos recursos à disposição do Serviço Sanitário Nacional ${ }^{51}$. (Tradução livre)

A Corte afirmou, assim, a constitucionalidade do Decreto-Lei n. 24/2013, convertido na Lei $n$. $57 / 2013^{52}$, que, privilegiando os princípios de continuidade terapêutica e as exigências de não interferência dos provimentos da autoridade judiciária, consentiu que os pacientes já tratados prosseguissem com o tratamento com células-tronco. As circunstâncias peculiares e excepcionais que induziram o legislador a não interromper o tratamento Stamina para os pacientes que estavam em tratamento, entretanto, não seriam aplicáveis a outros pacientes que solicitassem a terapia ${ }^{53}$.

Os pleitos de novos pacientes não justificariam, ao seu ver, que fosse derrogado o princípio da cautela no que concerne à utilização de novos medicamentos. Tal entendimento, afirmou a Corte Constitucional, é capaz, por si só, de excluir a alegada violação do preceito da igualdade por parte da legislação em questão e também de qualquer ofensa ao direito à saúde, ou do dever de solidariedade para com pacientes que não mais terão a chance de se submeter ao tratamento nas estruturas públicas italianas. Por último, o Tribunal Constitucional relembrou que inclusive a Corte Europeia de Direitos Humanos, situada em Estrasburgo, no julgamento do caso Durisotto versus Itália ${ }^{54}$, já havia decidido que a negativa de fornecimento e acesso à terapia segundo o método Stamina, conforme decisão de um juiz ordinário italiano em aplicação do Decreto n. $24 / 2013^{55}$, não ofenderia a isonomia nem o direito à saúde, sendo, na verdade, proporcional à sua proteção.

$\mathrm{Na}$ mesma ocasião, com relação à miríade de decisões conflitantes na Itália relativas à cura compassiva, a Corte Europeia afirmou inexistir ofensa ao artigo $14^{56}$ da Convenção Europeia de Direitos do Homem, que abriga o princípio da não discriminação. De acordo com a opinião expressa no caso D. H. e outros

\footnotetext{
${ }^{51}$ REPUBBLICA ITALIANA. CORTE COSTITUZIONALE. Sentenza n. 282 del 2012, cit.

${ }^{52}$ REPUBBLICA ITALIANA. PRESIDENZA DELLA REPUBBLICA. Decreto-legge 25 marzo 2013, n. 24, cit.

${ }^{53}$ Id. Ibid.

${ }^{54}$ COUR EUROPEENNE DES DROITS DE L'HOMME. Durisotto c. Italie. 2 mai 2014. Disponível em: <echr.coe. int>. Acesso em: 18 fev. 2016.

${ }^{55}$ REPUBBLICA ITALIANA. PARLAMENTO. Decreto-legge 25 marzo 2013, n. 24, cit.

56"Proibição de discriminação 0 gozo dos direitos e liberdades reconhecidos na presente Convenção deve ser assegurado sem quaisquer distinções, tais como as fundadas no sexo, raça, cor, língua, religião, opiniões políticas ou outras, a origem nacional ou social, a pertença a 1415 uma minoria nacional, a riqueza, o nascimento ou qualquer outra situação". CONVENÇÃO EUROPEIA DOS DIREITOS DO HOMEM. Disponível em: < http://www.echr.coe.int/Documents/Convention_POR.pdf>. Acesso em: 02 set. 2016.
} 
versus República Checa ${ }^{57}$, trazida à baila na decisão Durisotto, não basta que se trate de pessoas expostas à mesma situação para que ocorra a violação à isonomia em virtude de julgamentos díspares, mas é preciso que a distinção ocorrida no resultado dos litígios seja discriminatória. Segundo a jurisprudência da Corte Europeia, uma diferença de tratamentos seria discriminatória, para efeitos de seu artigo 14, quando não está presente justificativa objetiva e razoável, ou seja, quando não se esteja perseguindo um objetivo legítimo ou quando os meios para tanto empregados forem desproporcionais ${ }^{58}$.

Ainda que de certo modo com o respaldo ou, ao menos, em convergência com a orientação da Corte Europeia de Direitos Humanos, a decisão da Corte Constitucional italiana não deixou de receber críticas por parte da doutrina. A Corte teria se encontrado diante da necessidade de dar uma solução para uma escolha legislativa infeliz e, por essa razão, teria feito prevalecerem razões de oportunidade, no lugar de razões jurídicas ${ }^{59}$.

Tal argumento, no entanto, cai por terra ao se considerar que, como ensinou a Corte de Estrasburgo, não existe discriminação ou ofensa à isonomia quando se está diante de uma diferença decorrente de situação objetiva (inexistência de tratamento Stamina anterior) e de acordo com a razoabilidade (não expor pacientes a riscos desconhecidos e a tratamento experimental). Por outro lado, quem determina como devem ser gastos os recursos públicos destinados à saúde e quais as políticas públicas a serem implantadas não deve ser o juiz, mas o legislador, que possui legitimidade democrática para tanto.

\footnotetext{
${ }^{57}$ Caso de grande relevo, referente à discriminação levada a cabo na Republica Checa contra crianças ciganas, que eram colocadas em escolas especiais para alunos com atraso mental. A Corte reconheceu ofensa ao artigo 14 e condenou o Estado. (COUR EUROPEENNE DES DROITS DE L'HOMME.D.H. ET AUTRES c. RÉPUBLIQUE TCHĖQUE. Disponível em: <www.echr.coe.int>. Acesso em: 23 fev. 2016.

58“À cet égard, la Cour rappelle toutefois que pour qu'un problème se pose au regard de l'article 14, il ne suffit pas que l'on soit en présence d'une différence dans le traitement de personnes placées dans des situation comparables (D.H. et autres c. République tchèque [GC], n 57325/00, § 175, CEDH 2007 - IV, mais il faut aussi que la distinction litigieuse soit discriminatoire. Selon la jurisprudence, une distinction est discriminatoire au regard de l'article 14 si elle manque de justification objective et raisonnable, c'esta a dire si elle ne poursuit pas un but légitime ou s'il n'y a pas un rapport raisonnable de proportionnalité entre les moyens employés et le but visé (Rasmussen c. Danemark, 28 novembre 1984, § 38, série A n87; Burden c. Royaume-Uni [GC], n13378/05, § 60, CEDH 200.” (Tradução da autora: “'A este respeito, o Tribunal relembra, todavia, que para que uma questão seja posta com relação ao artigo 14, não é suficiente que se esteja na presença de uma diferença de tratamento de pessoas que se encontram em situações comparáveis (D.H e outros contra República Tcheca [GC], n. 57325/00, parágrafo 175, CEDH 2007 - IV), mas é necessário que a diferença em questão seja discriminatória. Segundo a jurisprudência, para que ela seja discriminatória, para fins do artigo 14, a diferença deve estar desprovida de justificação objetiva e razoável, ou seja, que ela não busque um fim legítimo ou que não exista uma relação razoável de proporcionalidade entre os meios utilizados e o objetivo perseguido".)

${ }^{59}$ SERENO, Giuliano. II Caso Stamina all'esame della Corte Costituzionale: un esito condivisibile sorretto da una motivazione lacunosa. 2015. AIC - Osservatorio Costituzionale. Disponível em: <www.osservatorioaic. it>. Acesso em: 03 nov. 2015.
} 
Cita-se aqui, para concluir a exposição do caso Stamina, reflexão de Milazzo, autor de excelente artigo sobre a judicialização da saúde na Itália:

[...] esse complexo de circunstâncias constitui exatamente o modo como o legislador aplicou o artigo 32 da Constituição ao tema da experimentação de medicamentos, levando em consideração ambas as intenções da disposição constitucional: a saúde coletiva, mas também (talvez, sobretudo) a saúde individual. Toda normativa existente é, na verdade, voltada a garantir ao paciente que não será submetido a tratamento que o coloque abaixo de um padrão mínimo de garantias [...]. Nesse complexo normativo encontram-se presentes procedimentos, opiniões técnicas e éticas, atividades de sujeitos constituídos ad hoc (AIFA, comitês éticos). Em outras palavras, o complexo normativo e o modo pelo qual o legislador quis garantir ao artigo 32 essa particularíssima perspectiva. Certo ou errado, constitucional ou inconstitucional, perfeito ou carente, foi esse o modo como o legislador encontrou a síntese, efetuou o balanceamento,fez atuar a Constituição.

$\mathrm{Na}$ verdade, as decisões sobre a Fundação Stamina propõem uma aplicação da Constituição, do artigo 32, que substancialmente ultrapassa o modelo pretendido pelo legislador para fazer atuar aquele princípio constitucional. Um uso da Constituição por parte dos juízes que extrapole este modelo é realmente desejável? Ainda que somente em via cautelar, uma aplicação da Constituição que substitui a escolha legislativa pela sensibilidade e pelo alcance dos valores expressos pelo juiz é verdadeiramente admissível, excetuando-se a possibilidade de recurso à Corte Constitucional? É verdadeiramente esse uso direto da Constituição ao qual os constitucionalistas encontram-se afeiçoados? O artigo 32 tutela também a esperança? Também o desespero? ${ }^{60}$ (Tradução livre)

\section{Considerações finais}

Após esse breve estudo dos leading cases norte-americano e italianos, percebe-se que o STF, com a última decisão liminar que suspendeu a lei que determinava o fornecimento da pílula do câncer à população, coloca o Brasil numa tendência semelhante àquela dos outros dois países, no que diz respeito à impossibilidade de doentes se submeterem a tratamentos experimentais, não registrados e ainda em curso, como forma de terapia, e, ainda, quanto à obrigação do Estado de custeá-los e fornecê-los.

\footnotetext{
${ }^{60}$ MILAZZO, P. Quel terribile amore per la Costituzione. II diritto alla salute comprende anche il diritto alla speranza? Jusbox, 10 fev. 2013.p. 2 ss. Disponível em: <jusbox.net>. Acesso em: 25 fev. 2016.
} 
De fato, os julgados dos tribunais brasileiros e do STF referentes ao direito à saúde, sobretudo quando requeridas terapias experimentais, tendiam a faltar com a técnica jurídica e a se basear em argumentos emotivos e compassivos, dando um conteúdo subjetivo e quase emocional a essa garantia constitucional. Entretanto, parece que a decisão final da ADI 5501 da Lei n. 13.269/2016 trará um amadurecimento jurisprudencial que reverterá tal trend, como ocorrido na jurisprudência da Corte Constitucional italiana com o caso Stamina.

Com efeito, a Corte italiana - que, num primeiro momento, havia acolhido as pretensões de submissão e fornecimento pelo Estado do multitratamento di Bella, como forma de garantia e concretização do direito à saúde - foi obrigada a rever seu posicionamento no caso Stamina, em decorrência do resultado negativo da terapia di Bella e do gasto enorme, e em vão, dela decorrente. O mais interessante é que, posteriormente, os testes oficiais demonstraram que a decisão da Corte foi acertada, porque tampouco esse tratamento produzia os resultados esperados.

Não somente a comunidade jurídica, mas também os agentes médicos aplaudiram a mudança de entendimento da Corte. Gilberto Corbellini, em palestra na Universidade de Sapienza (Roma), em palestra sobre aspectos médicos e éticos dos casos di Bella e Stamina, classificou-os como um "regresso moral da medicina" sob o ponto de vista bioético ${ }^{61}$. Na verdade, sob uma perspectiva médica, os casos judiciais com pretensão de terapia experimental cometem o erro inescusável de colocar no mesmo plano a medicina baseada em evidências e aquela baseada em engano e ilusão, confundindo a liberdade de cura com um inexistente direito de pedir ao Estado o custeio de qualquer tratamento que se deseje receber. Nas palavras do professor, esse tipo de pretensão é um "ataque à epistemologia científica", pois "anedotas" são confundidas com provas e, caso se pense que sem um procedimento científico racional possam existir provas, estar-se-á diante de uma regressão da medicina ao empirismo ${ }^{62}$.

Ademais, ao se dar judicialmente a um paciente a possibilidade de se submeter a uma terapia compassiva, se está desprestigiando o direito dele mesmo de ser informado de modo verdadeiro, transgredindo-se a obrigação moral do médico de não submeter o paciente a riscos inúteis, mas de tratá-lo de acordo com os melhores e mais eficazes protocolos. Por outro lado, comete-se ainda enorme injustiça social e lesão ao erário, em decorrência do dinheiro público desperdiçado com o pagamento de pseudostratamentos médicos ou experimentações sem qualquer conteúdo científico. Nesse mesmo sentido, essas decisões judiciais arbitrárias também comprometem a autonomia do médico. Isto porque, numa era de medicina baseada em evidências, a autonomia do médico não corresponde a fazer aquilo que lhe dita a consciência ou seus sentimentos, mas constitui a utilização racional e inteligente dos recursos disponíveis.

\footnotetext{
${ }^{61}$ CORBELLINI, M. Dal Caso Di Bella al Caso Stamina: bioetica di un cocktail tossico. Palestra à Universidade de Sapienza. Roma, 2014.

${ }^{62}$ No original: "Sono un attacco all'epistemologia scientifica”. (Id. Ibid.).
} 
As mencionadas sentenças confundem, igualmente, a compaixão com a permissão para se cometerem atos danosos aos pacientes, sem considerar sua esperança ilusória e sua dignidade. Ofendem, assim, a dignidade humana, pensando protegê-la, na medida em que se toma proveito da fragilidade do paciente que deseja desesperadamente a cura, oferecendo-lhe terapia que, na verdade, em termos médicos e científicos, inexiste ${ }^{63}$.

Feitas essas considerações, e diante da necessidade exigida pelos casos emblemáticos estudados de balancear o "direito à esperança" dos pacientes - seu "right to try" - com as normas técnicas impostas pela Administração Publica para os novos medicamentos que surgem prometendo curas milagrosas, propomos o caminho das normas de boas práticas clínicas como parâmetro orientador do debate.

De fato, o guia de boas práticas clínicas surge, nessa conjuntura, como zíper entre ciência, ética e direito. Deve ser o ponto de encontro entre a ciência médica, o aspecto ético relativo à dignidade, ao desespero e à esperança do doente, e a previsão constitucional do direito à saúde, assim como suas normas afins ${ }^{64}$.

As normas de Boas Práticas Clínicas possuem os seguintes princípios:

- conduta ética: pesquisa científica conduzida de acordo com três princípios éticos basilares, quais sejam, respeito à pessoa, beneficência e justiça;

- descrição da Pesquisa em um Protocolo (nenhum dos casos estudados possuía protocolo claro disponível, mas formas múltiplas e variadas de terapia. No caso da pílula do câncer, a USP deixa tal aspecto bastante claro em seu site na internet e, ainda que o paciente haja obtido judicialmente o fármaco, a universidade não poderá precisar como deverá usá-lo.);

\footnotetext{
${ }^{63}$ No mesmo sentido: "Se não existe base científica para o tratamento, então não tem sentido em se falar de 'direito à esperança', porque não se trata de esperança, se trata de ilusão." (PARIS, Davide. I rischi di una giurisprudenza "compassionevole". Riflessioni sull'operato della magistratura ordinaria nel caso Stamina. 31 lugl. 2105. Disponível em <http://www.forumcostituzionale.it/wordpress/wp-content/ uploads/2015/07/paris.pdf >. Acesso em: 5 jan. 2016).

${ }^{64}$ Dentro desse quadro de normas técnicas, no âmbito do desenvolvimento de experimentos, existe um decreto na Itália (Art. 1, c. 3 del d. Igs. 211/2003.), que recebeu no ordenamento jurídico italiano as normas de boas práticas adotadas pela Comissão Europeia (Good Clinical Pratice). Essas normas garantem a tutela dos direitos, da segurança e do bem-estar dos sujeitos, assegurando a credibilidade dos dados concernentes à experimentação clínica. De fato, constituem um conjunto de requisitos em matéria de qualidade no campo ético e científico, reconhecidos em nível internacional e que devem ser observados em todas as fases da experimentação. No Brasil, por outro lado, o Conselho Nacional de Saúde do Ministério da Saúde elaborou a normativa em pesquisa medica, resolução n.1/88, no mesmo ano em que, nos Estados Unidos, o conceito de boas práticas clínicas foi consolidado pela Food and Drug Administration (FDA), regulando aspectos éticos, de biossegurança e de vigilância sanitária nas pesquisas. A partir de 1995, a Organização Mundial da Saúde (OMS) passou a adotar os princípios de BPC como recomendação formal a todos seus países filiados. No ano seguinte, o Brasil, seguindo as orientações da Conferência Internacional de Harmonização, pela Plenária do CNS, aprovou a resolução 196/96 CNS/MS. De fato, o ano de 1996 foi um divisor de águas na evolução da pesquisa clínica, após a reunião do comitê diretivo da Conferência Internacional de Harmonização (ICH) e editoração do Manual Tripartite Harmonizado da ICH, que tinha como objetivo fornecer padrão único de práticas regulatórias para a União Europeia, o Japão e os Estados Unidos. Após esse período, outras resoluções complementares vieram a corroborar o aprimoramento das boas práticas clínicas no âmbito da pesquisa clínica nacional. (LARANJEIRA, Ligia Nali, et. al. Boas práticas clínicas: padrão de pesquisa clínica. Rev Bras Hipertens, v. 14, n. 2, p. 121-123, 2007).
} 
- identificação dos riscos;

- cotejo risco-benefício;

- revisão por comitê ético independente;

- protocol compliance (conformidade com o protocolo);

- consentimento informado do paciente;

- revisão contínua;

- qualificação do pessoal ${ }^{65}$.

Em um sentido filosófico, por outro lado, as normas técnicas (representadas, no debate, pelas Boas Práticas Clínicas) podem ser consideradas como "ambiente" do homem contemporâneo, como ensina Galimberti $i^{66}$. De fato, a técnica na sociedade de hoje teria substituído a natureza e constituiria o novo hábitat humano.

O problema, no entanto, é que a humanidade ainda carrega a bagagem do homem pré-tecnológico e, por isso, continua a viver um humanismo arcaico, no qual o homem age com vistas a um objetivo e movido por seus próprios sentimentos. A técnica que permeia o mundo moderno, no entanto, não tende a um escopo, não abre cenário à salvação, não revela verdades; a técnica somente "funciona" ${ }^{"}$.

Em virtude disso, o homem, mergulhado ainda no velho Humanismo, tem dificuldade de aceitar essa mudança de paradigmas e, vendo a técnica com certa ansiedade, pensa poder controlá-la com sua própria vontade. Como analfabeto emotivo, assiste à irracionalidade que jorra da perfeita racionalidade da organização técnica, na qual não está presente qualquer sentido reconhecível ${ }^{68}$. Em tal conjuntura, e por causa desse descompasso entre humanidade, técnica e ciência, surge o debate das curas compassivas. O homem precisa de uma ampliação psíquica capaz de compensar sua inadequação atual. Assim, os juízes, diante das pretensões de curas compassivas e experimentais, considerando essa situação, devem tentar contrabalançar a necessidade emotiva do homem (seu desespero) com a insuperável realidade técnica moderna.

Adotando essa postura, os juízes atuarão de forma mais isonômica e imparcial, na medida em que, na técnica, o poder é submetido à ciência. Na verdade,

\footnotetext{
${ }^{65}$ v. WORLD MEDICAL ASSOCIATION. Declaration of Helsinki. 2008 [cited 2012 Oct.]. Disponível em: <http:// www.wma.net/ en/30publications/10policies/b3/17c.pdf.>. Acesso em: 05 mar 2016; WHO. Guidelines for Good Clinical Practice (GCP) for Trials on Pharmaceutical Products. Geneva, Switzerland, 1995. p. 97-137. (Technical Report Series no. 850).

${ }^{66}$ GALIMBERTI, U. Psiche e tecniche: I'uomo nell'età della técnica. Milano: La Feltrinelli, 2002.

${ }^{67} \mathrm{ALBINI}$, C. Croce e techne. Confronto con Umberto Galimberti. Dialegesthai: rivista telematica di filosofia, anno 3, 2001. Disponível em <http://mondodomani.org/dialegesthai/cha01.htm>. Acesso em: 10 mar. 2016.

${ }^{68}$ ld. Ibid.
} 
a técnica, diferente da política e dos indivíduos, não possui intenção nem ideologias ${ }^{69}$. Ela deseja e busca somente sua própria potencialização, uma vez que "deseja a si mesma"70. Desta maneira, diante dessa realidade e da idealizada imparcialidade dos magistrados, os tribunais não poderiam acatar pretensões em que são desconsideradas as normas técnicas em virtude de suposta urgência ou necessidade individual.

Por outro lado, seguindo-se o mesmo raciocínio, a liberdade individual também não deveria permitir que alguém se submetesse a tratamento cuja terapia e cujo protocolo não tivessem seguido as normas técnicas aplicáveis. Como consequência, não há que se falar em "direito à esperança", mas somente em direito à saúde. No direito à saúde, a técnica não abre espaço para a esperança subjetiva, mas para novas possibilidades reais decorrentes de pesquisa realizada de acordo com as boas práticas. O Tribunal de Roma, em acertada decisão que negou o tratamento Stamina, corrobora esse entendimento, dizendo:

Se é verdade que o artigo 32 não impõe um modelo abstrato de medicina, também é verdade que um balanceamento razoável entre o direito subjetivo à saúde e o princípio [...] da indisponibilidade da vida e da integridade psicofísica da pessoa pode dar-se somente na medida em que fundamente as escolhas sobre tratamento terapêutico nos elementos e nas circunstâncias de fato as mais objetivas e controláveis possíveis, em circunstâncias falsificáveis. Isso exclui uma abordagem subjetiva/intuitiva não fundada em evidências clínicas de tratamento, mas na esperança ou, mais em geral, na mera fidúcia do médico ${ }^{71}$. (Tradução livre)

\footnotetext{
${ }^{69} \mathrm{Em}$ entrevista no Brasil à Unisinos, o próprio Galimberti nos deu este exemplo: “Não se trata de afirmar algo como 'temos que curar o câncer'. A ciência não funciona assim. A tecnociência opera a partir da seguinte lógica: 'deve-se estudar certo aminoácido por 20 anos'; 'estude esta proteína por dez anos'. Se perguntássemos qual é o objetivo, o cientista responderia 'não sei'. Ele argumentaria que é necessário conhecer tudo aquilo que é possível e, se com o resultado desses conhecimentos tivermos uma vantagem para a humanidade, OK, mas este não é o objetivo e sim o resultado final de uma série de procedimentos. Ninguém projetou a clonagem humana, apenas viu-se que era possível." ALENCAR, R.A. Umberto Galimberti na Idade da Técnica. Disponível em <http://robertoantonioalencar.blogspot.it/2014/12/ umberto-galimberti-na-idade-da-tecnica.html>. Acesso em: 07 mar. 2016.

${ }^{70}$ No original: "La tecnica contiene una volontà di dominio che vuole in primo luogo il proprio infinito potenziamento: “vuole se stessa'”. (ALBINI, 2013).

${ }^{71}$ Come observa o Tribunal de Roma na sentença que negou o recurso do art. 700 c.p.c. contra o Hospital Spedali Riuniti: "se è vero che l'art. 32 non impone un modello astratto di medicina, è anche vero che un ragionevole bilanciamento fra il diritto soggettivo alla salute ed il principio [...] della indisponibilità della vita e dell'integrità psico-fisica della persona, può trovarsi solo a condizione di fondare le scelte sul trattamento terapeutico su elementi e circostanze di fatto il più possibile oggettive e controllabili, su circostanze falsificabili. Ciò esclude un approccio soggettivo/intuitivo non fondato su evidenze cliniche del trattamento ma sulla speranza o, più in generale, sulla mera fiducia del guaritore". (Se é verdade que o Artigo 32 não impõe um modelo abstrato de medicina, é também verdade que um razoável balanceamento entre o direito subjetivo à saúde e o princípio [...] da disponibilidade da vida e da integridade psico-física da pessoa pode se realizar somente quando houver condições de fundamentar as escolhas de tratamento terapêutico em elementos e circunstâncias de fato, o mais objetivas e controláveis, em circunstâncias falsificáveis. Isto exclui uma abordagem subjetiva/ intuitiva não fundada em evidências clínicas de tratamento mas na esperança ou, mais em geral, na mera fidúcia do 'curandeiro' [criador da terapia nova].
} 
Não se pode, de fato, falar em direito à saúde que não esteja intimamente ligado ao cumprimento das normas técnicas sanitárias e de pesquisa. $\mathrm{O}$ "direito de tentar" (right to try) existe, mas não como justificativa para se afastarem as normas técnicas e se preterirem etapas nos protocolos técnicos, e sim como possibilidade de se tomar proveito daqueles resultados seguros e positivos, obtidos por meio do procedimento correto das boas práticas. Caso contrário, não será possível falar em direito à saúde, mas na liberdade individual de se submeter a terapias fantásticas, fórmulas de contos da carochinha e fontes da juventude.

\section{Referências}

AGENZIA ITALIANA DEL FARMACO. Multittrattamento di Bella: risultati della sperimentazione. Disponível em: <http://www.agenziafarmaco.gov.it/it/content/ilmultitrattamento-di-bella-risultati-della-sperimentazione>. Acesso em: 03 mar. 2016.

ALBINI, C. Croce e techne. Confronto con Umberto Galimberti. Dialegesthai: rivista telematica di filosofia, anno 3, 2001. Disponível em <http://mondodomani.org/dialegesthai/ cha01.htm>. Acesso em: 10 mar. 2016.

ALENCAR, R.A. Umberto Galimberti na Idade da Técnica. Disponível em <http:// robertoantonioalencar.blogspot.it/2014/12/umberto-galimberti-na-idade-da-tecnica.html $>$. Acesso em: 07 mar. 2016.

ALFONSO-GOLDFARB, A. M.; MAIA, C. A. (Coords.) História da ciência: o mapa do conhecimento. Rio de Janeiro: Expressão e Cultura; São Paulo: EDUSP, 1995. 968 p. (América 500 anos, 2).

BUZZI, F.; TASSI, G. La supremazia dei giudici, la sudditanza della scienza medica e la cedevolezza della governance amministrativa e politica in materia di trattamenti sanitari impropriamente qualificati cine compassionevole. Rivista Italiana di Medicina Legale (e del Diritto in campo sanitario). n. 2, p. 417-430, 2014.

CAPOCCI, M; CORBELLINI, G. Le cellule della speranza: il caso Stamina tra inganno e scienza. Torino: Codice Edizioni, 2014. 192p.

CASTELLANETA, Domenico. Pretore ordina la cura di Bella per un bimbo malato di tumore. La Repubblica, Itália, 17 dez. 1997. Disponível em: <http://ricerca.repubblica.it/repubblica/ archivio/repubblica/1997/12/17/pretore-ordina-la-cura-di-bella-per.html?refresh_ce>. Acesso em: 27 jun. 2016.

CONVENÇÃO EUROPEIA DOS DIREITOS DO HOMEM. Disponível em: < http://www. echr.coe.int/Documents/Convention_POR.pdf>. Acesso em: 02 set. 2016.

CORBELlini, M. Dal Caso Di Bella al Caso Stamina: bioetica di un cocktail tossico. Palestra à Universidade de Sapienza. Roma, 2014.

D’AMICO, G. Caso Stamina: la lotta per la salute. Disponível em: <www.forumcostituzionale. it>. Acesso em: 01 fev. 2016. 
D'AMICO, G. Il voto compassionevole del diritto e la dura scientia: a proposito del metodo Stamina. Quad. Cost, n. 2, p. 420-424, 2013.

DEMURO, G. La ricerca scientifica e il diritto alla salute. Rivista Telematica Giuridica dell' Associazione Italiana dei Costituzionalisti, n. 4, p. 6, 06/12/2013. Disponível em: <http://www. associazionelucacoscioni.it/sites/default/files/documenti/4_2013_DeMuro.pdf $>$.

DI BELLA. Cronistoria degli anni "caldi". Dalle prime sperimentazioni alla "bocciatura" dell'Iss. Quotidiano Sanità, Itália, 27 fev. 2012. Disponível em: $<$ http://www.quotidianosanita. it/cronache/articolo.php?approfondimento_id=1758>. Acesso em: 27 jun. 2016.

DOSSIER Stamina. Disponível em: <http://www.biodiritto.org/novita/news/item/330-dossierstaminali>. Acesso em: 28 jun. 2016.

EL DIB, Regina P. Como praticar a medicina baseada em evidências. J Vasc Bras, v. 6, n. 1, 2007. Disponível em: <http://www.scielo.br/pdf/jvb/v6n1/v6n1a01.pdf > . Acesso em: 23 maio 2016.

FALLETTI, Elena. Riflessioni sulle possibili cause del cortocircuito giuridico-istituzionale provocato dalla vicenda Stamina. Questione di Giustizia. Magistratura Democratica. Disponível em: <http://www.questionedigiustizia.it>. Acesso em: 15 fev. 2016.

GALIMBERTI, U. Psiche e tecniche: l'uomo nell'età della técnica. Milano: La Feltrinelli, 2002.

GIUPPONI, Lisa. Stamina, storia di una vicenda italiana: terapie staminali e diritto alla salute. Disponível em: <http://www.macsis.unimib.it/wp-content/uploads/2014/01/Revisione-1Lisa-Giupponi-Stamina-Storia-di-una-vicenda-italiana-.pdf >. Acesso em: 17 mar. 2016.

LARANJEIRA, Ligia Nali, et. al. Boas práticas clínicas: padrão de pesquisa clínica. Rev Bras Hipertens, v. 14, n. 2, p. 121-123, 2007.

MEDBUNKER. Dossier di Bella. Disponível em: <http://medbunker.blogspot.it/p/dossierdi-bella.html>. Acesso em: 27 jun. 2016.

MILAZZO, P. Quel terribile amore per la Costituzione. Il diritto alla salute comprende anche il diritto alla speranza? Jusbox, 10 fev. 2013. Disponível em: <jusbox.net>. Acesso em: 25 fev. 2016.

MOERTEL, C. et al. A clinical trial of amygdalin (Laetrile) in the treatment of human cancer. New England Journal of Medicine, v. 306, n. 4, p. 201-206, Jan. 1982.10.1056/NEJM198201283060403.

OLIVEIRA, G. et al. Ensaios clínicos: princípios e prática. Brasília: Ministério da Saúde, Agência Nacional de Vigilância Sanitária; 2006.

PACE, T. Diritto alla salute o alla speranza? L'accesso al metodo Stamina per i pazienti affetti da patologie incurabili. Nuova Giur. Civ, n. 2, p. 133-138, Feb. 2014.

PARIS, Davide. I rischi di una giurisprudenza "compassionevole". Riflessioni sulloperato della magistratura ordinaria nel caso Stamina. 31 lugl. 2105. Disponível em <http://www. forumcostituzionale.it/wordpress/wp-content/uploads/2015/07/paris.pdf >. Acesso em: 5 jan. 2016. 
PETERSEN, James C.; MARKLE, Gerald E. Politics and science in the Laetrile Controversy, Social Studies of Science, n. 9, p. 139-166, May, 1979. Disponível em: <http://sss.sagepub. com>. Acesso em: 29 fev. 2016.

PORTALE Médico Scientifico della Associazione "Giuseppe di Bella”. Sentenze giudiziarie a favore di pazienti in cura. Disponível em: <http://http://www.metododibella.org/it/ SENTENZE-GIUDIZIARIE-a-favore-di-pazienti-in-cura.html>. Acesso em: 14 jan. 2016.

POTESTIO, Andrea. La Liberta nellera della técnica. In: D’ALESSANDRO, Paolo; POTESTIO, Andrea (a cura di). Filosofia della técnica. Milano: LED, 2006.

PROCURA DELLA REPUBBLICA. Avviso di conclusione indagini preliminari della Procura della Repubblica presso il Tribunale di Torino. 22 aprile 2014. Disponível em: <www.biodiritto.org $>$.

RELMAN, A. Closing the books on Laetrile. New England Journal of Medicine, n. 306, p. 236, 1982. 10.1056/NEJM198201283060410.

REPUBBLICA ITALIANA. Ministero della Sanità. Bollettino d'informazione sui farmaci. Il Multitrattamento Di Bella - risultati della sperimentazione. Disponível em $<$ http://www. salute.gov.it/imgs/C_17_pubblicazioni_251_allegato.pdf>. Acesso em: 10 ago. 2015.

SARRA, Claudio. Questioni pregiudiziali: una prospettiva epistemologica sui rapporti tra neuroscienze e diritto. Etica e Politica/Ethics and Politics, v. 16, n. 2, p. 64-100, 2014.

SCALERA, Antonio. Brevi note a margine del caso Stamina. Famiglia e diritto, n. 10, p. 939-943, 2013. Disponível em: <http://users2.unimi.it/unistem/wp/wp-content/uploads/ Scalera-fadi-101.pdf>.

. Il Caso Stamina tra diritto e scienza. Le Nuove Leggi Civili Commentate, anno 30, n. 2, p. 75-84, Feb. 2014.

SERENO, Giuliano. Il Caso Stamina allesame della Corte Costituzionale: un esito condivisibile sorretto da una motivazione lacunosa. 2015. AIC - Osservatorio Costituzionale. Disponível em: <www.osservatorioaic.it>. Acesso em: 03 nov. 2015.

SOUSA, M.S.A.; FRANCO, M.A.G.; MASSUD FILHO, J. A nova declaração de Helsinque e o uso de placebo em estudos clínicos no Brasil: a polêmica continua / The new declaration of Helsinki and the use of placebo in Brazilian clinical trials: controversy remains. Rev Med, São Paulo, v. 91, n. 3, p. 178-188, jul./set. 2012. Disponível em: <www.revistas.usp.br/revistadc/ article/download/58980/61966>.

TALLACCHINI, M. Stato di scienza? Tecnoscienza, policy e diritto. Federalismo.it, n. 16, 2005. Disponível em: <http://federalismi.it/document/editoriale/Tallacchini.pdf >. Acesso em: 20 fev. 2016.

TIEMAN, J. The facebook frontier: compelling social media can transform health dialogue. Health Prog, v. 93, n. 2, p. 82-83, Mar./Apr. 2012. 
TOMASI, M. Il diritto alla salute fra comprensione del bisogno e ragioni della scienza:note a margine della vicenda Stamina. Rassegna di diritto pubblico europeo, anno 12, n. 1, p. 63-85, genn./giug. 2013.

VARONESI, Paolo. Al crocevia del caso Stamina e dei suoi problemi costituzionali. Disponível em: <http://www.forumcostituzionale.it/wordpress/wp-content/uploads/2015/01/veronesi.pdf > .

VETTORI, Nicoletta. Sistema normativo aperto, rigore del metodo scientifico e diritto alla salute: il difficile ruolo di mediazione delle istituzioni pubbliche (a proposito del caso Stamina). Biolaw journal, Rivista di Biodiritto, n. 1 2015. Disponível em: <http://www.biodiritto.org/ojs/ index.php?journal=biolaw\&page $=$ article\&op $=$ view $\&$ path $\% 5 B \% 5 \mathrm{D}=51 \&$ path $\% 5 \mathrm{~B} \% 5 \mathrm{D}=44>$.

VIANO, C.A. Diritti sulla vita. Quaderni Laici, Torino, n. 13, 2014.

WHO. Guidelines for Good Clinical Practice (GCP) for Trials on Pharmaceutical Products. Geneva, Switzerland, 1995. (Technical Report Series no. 850).

WORLD MEDICAL ASSOCIATION. Declaration of Helsinki. 2008 [cited 2012 Oct.]. Disponível em: <http://www.wma.net/ en/30publications/10policies/b3/17c.pdf.>. Acesso em: 05 mar 2016.

Elina Magnan Barbosa - Doutoranda em Direito na Universidade de Pisa (Itália); mestre em Direito pela Universidade de Brasília; especialista em Direito Público pelo Instituto Brasilisiense de Direito Público; especialista em Direito Ambiental e Recursos Hídricos pela Universidade Cândido Mendes. Advogada pública; procuradora do Distrito Federal, Procuradoria do Meio Ambiente, Patrimônio Urbanístico e Imobiliário. Dipartimento Pisa/ Toscana, Itália.E-mail: elina_magnan@yahoo.com.br. 